\title{
The Effects of Grease Filling Amount on Temperature Performance of High-Speed Sealed Angular-Contact Ball Bearings
}

\author{
J.X.Xue ${ }^{1, a}$, Y.Zhang ${ }^{1, b}$ and L.N.Wang ${ }^{1, c}$ \\ ${ }^{1}$ School of Mechanical Engineering, Henan University of Science \& Technology, Luoyang, China \\ axjx19652000@163.com, bzhangypds@163.com, cwanglinazs@163.com
}

Keywords: high-speed sealing angular-contact ball bearing, Optimum filling grease, Bearings temperature performance, Static space ratio

\begin{abstract}
More than 80 percentages of high-speed sealed angular-contact ball bearings are lubricated by grease. The grease filling amount has a great influence on bearing performance and service life. The static space ratio $\lambda_{s}$ and movement space ratio $\lambda_{d}$ were analyzed and calculated in this paper. Bearing temperature performance tests were conducted using different amounts of filling grease. The temperature performance of bearings with different grease was compared under different working conditions. The optimum grease filling amount of this kind of bearings is obtained through experiments. The conclusion can provide reference for bearing application.
\end{abstract}

\section{Introduction}

High-speed sealed angular-contact ball bearing has the advantages of simple structure, easy assembly, low heat generation, etc. The sealing bearings and open bearings have the same size and standard series. They are often matched with electric spindles which are widely used in the machine tool industry [1, 2]. In a rolling bearing, fatigue life, friction, temperature rising, vibration and so on are all affected by the grease. Without proper lubrication, the bearing will not work properly. Excessive or insufficient grease will have a certain impact on the performance of bearing, so the determination of the amount of grease is particularly important [3, 4].

In actual applications, for the need of determining the amount of grease accurately in the high speed sealed angular contact ball bearings, national standards were often used as the basis. Many bearing companies do not have accurate data of grease filling amount [5]. Therefore, it is of great practical significance to analyze the filling grease amount of high-speed sealed angular-contact ball bearing.

\section{Determination of Sealing Space}

Sealing full space V: two sealing rings, the bearing inner ring and outer ring wrap an annular space. This space minus the volume of cage and rolling elements gains the $\mathrm{V}$. In order to facilitate the calculation, the bearing is carried out simplified as follows: all dimensions of the bearing are given by the national standard, and the influences of the tolerances are ignored during the calculation. Effects of sealing ring lip clearance, transmutation as well as clearance on the inner space of the bearing are ignored. Sealing full space of high-speed sealed angular-contact ball bearing can be obtained by the following equation:

$$
\mathrm{V}=\mathrm{V}_{0}+\mathrm{V}_{\mathrm{i}}+\mathrm{V}_{\mathrm{cr}}+\mathrm{V}_{\mathrm{l}}+\mathrm{V}_{\mathrm{s} 1}+\mathrm{V}_{\mathrm{s} 2}+\mathrm{V}_{\mathrm{t}}-\mathrm{V}_{\mathrm{c}}-\mathrm{V}_{\mathrm{r}}
$$

Here, $V_{o}$ is the outer ring channel volume. $V_{i}$ is the inner ring channel volume. $V_{c r}$ is the circular ring volume between inner and outer rings. $V_{l}$ is the volume of slope part, located in the inner ring lock. $\mathrm{V}_{\mathrm{s} 1}$ is the volume of the sealing ring on the side of the outer ring. $\mathrm{V}_{\mathrm{s} 2}$ is the volume of the sealing ring on the side of the inter ring. $V_{t}$ is the volume located between the step on both sides of the inner ring and the sealing ring. $\mathrm{V}_{\mathrm{c}}$ is the Bakelite cage volume. $\mathrm{V}_{\mathrm{r}}$ is the volume of the cage. 
Sealing movement space Vd: when the bearing inner ring is rotated, the space of rolling element and cage is shown in A area in fig.1. Sealing static space Vj: when the bearing inner ring is rotated, it will not be driven by the rotation of the sealed space as shown in B area in Fig.1. Movement space ratio $\lambda \mathrm{d}$ : with the ratio of sealing movement space $\mathrm{Vd}$ and sealing full space $\mathrm{V}$, it can be given as

$$
\lambda_{\mathrm{d}}=\mathrm{V}_{\mathrm{d}} / \mathrm{V} \text {. }
$$

Static space ratio $\lambda_{s}$ : the ratio of sealing static space $V_{j}$ and sealing full space $V$, it can be given as

$$
\lambda_{\mathrm{s}}=\mathrm{V}_{\mathrm{j}} / \mathrm{V} \text {. }
$$

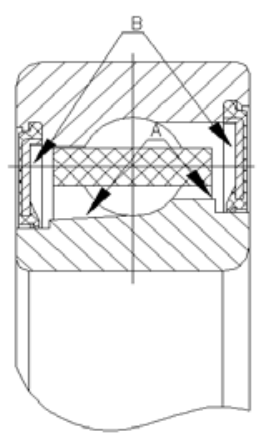

Fig.1. H7005C-2RZ bearing inner space

\section{Experimental Conditions and Methods}

The selection of the experimental bearings should ensure the same parameters. Experiments were divided into four groups. The grouping method is in accordance with the amount of filling grease. The ratios of grease are 20, 30, 40, 50 percentages respectively. The amount of filling grease is give by

$$
\mathrm{W}=\mathrm{g} \times \rho \times \mathrm{V} .
$$

Where $\mathrm{W}$ is the filling grease amount. $\mathrm{g}$ is the filling grease amount ratio. $\rho$ is the grease density.

Table 1 shows some relevant data of the experiments, including the number of bearings, the vibration data, the weight of bearings before filling grease, the weight of bearings after adding grease and the measurement parameters after the experiment. One more important thing worth concerning is

\begin{tabular}{|c|c|c|c|c|c|c|c|c|c|c|c|}
\hline \multirow[b]{2}{*}{ No. } & \multirow{2}{*}{$\begin{array}{l}\text { Bearing } \\
\text { number }\end{array}$} & \multicolumn{4}{|c|}{ Rotation precision $[\mu \mathrm{m}]$} & \multirow{2}{*}{$\begin{array}{r}\text { Vibration } \\
{[\mu \mathrm{m} / \mathrm{s}]} \\
\end{array}$} & \multirow{2}{*}{$\begin{array}{c}\text { Weight } \\
\text { [g] }\end{array}$} & \multirow{2}{*}{$\begin{array}{c}\text { Weight } \\
\text { after filling } \\
\text { [g] }\end{array}$} & \multirow{2}{*}{$\begin{array}{c}\text { Grease } \\
\text { amount } \\
{[\mathrm{g}]}\end{array}$} & \multirow{2}{*}{$\begin{array}{c}\text { Weight } \\
\text { after } \\
\text { experiment( } \\
{[\mathrm{g}]}\end{array}$} & \multirow{2}{*}{$\begin{array}{c}\text { Weight after } \\
\text { removal of } \\
\text { visible grease } \\
{[\text { g] }}\end{array}$} \\
\hline & & $\mathrm{K}_{\mathrm{i}}$ & $\mathrm{S}_{\mathrm{i}}$ & $\mathrm{K}_{\mathrm{i}}$ & $\mathrm{S}_{\mathrm{e}}$ & & & & & & \\
\hline \multirow[t]{2}{*}{1} & 74 & 1 & 3 & 2 & 3 & 40 & 69.43 & 70.06 & 0.63 & 70.03 & 69.73 \\
\hline & 1888 & 1 & 2 & 2 & 3 & 41 & 69.61 & 70.23 & 0.62 & 70.23 & 69.82 \\
\hline \multirow[t]{2}{*}{2} & 526 & 1 & 2 & 2 & 3 & 40 & 69.60 & 70.55 & 0.95 & 70.52 & 69.84 \\
\hline & 219 & 1 & 2 & 2 & 3 & 39 & 69.66 & 70.58 & 0.92 & 70.58 & 69.97 \\
\hline \multirow[t]{2}{*}{3} & 928 & 2 & 3 & 2 & 4 & 43 & 69.95 & 71.25 & 1.3 & 71.25 & 70.28 \\
\hline & 1815 & 1 & 2 & 2 & 3 & 42 & 69.2 & 70.57 & 1. 28 & 70.56 & 69.57 \\
\hline \multirow[t]{2}{*}{4} & 2197 & 2 & 2 & 2 & 3 & 38 & 69.7 & 71.33 & 1.58 & 71. 06 & 70.02 \\
\hline & 2190 & 1 & 3 & 2 & 3 & 42 & 69.7 & 71.32 & 1. 60 & 71. 01 & 70.02 \\
\hline
\end{tabular}
that must be done in the electronic balance to the bearing weighing before the experiments.

Table 1.Bearing test parameters 
Bearing temperature rising performance tests were carried out on the bearing life testing machine. The testing machine adopts high speed electric spindle to drive the bearing test header. Temperature, vibration, current, rotational speed, and axial and radial loads can be monitored in real time by the sensors and rendered by the computer. Then experiments were carried out according to the procedures set in advance. The bearing life test machine can allow up to 4 sets of bearing experiment at the same time, with each group only two sets of the same bearings to be tested.

First, the bearings that filling grease was mounted on the bearing test machine to undergo temperature rising tests during running-in phase. The above experiments stopped when the monitoring data changed smoothly, then temperature rising tests during stationary phase were carried out for 6 hours. Bearing load was set to a fixed value with the axial load 140N per minute, and the radial load $50 \mathrm{~N}$ per minute. Temperature sensors probe headed to the outer ring of tested bearing. In the course of the experiment, room temperature must be constant. Table 2 shows the corresponding relationship between speed and time. The experimental head structure of the bearing test machine was shown in fig. 2.

Table 2.Speed and time

\begin{tabular}{cccc}
\hline \multicolumn{2}{c}{ Running-in phase } & \multicolumn{2}{c}{ Stationary phase } \\
\hline Speed[r/min] & Time[min] & Speed[r/min] & Time[min] \\
\hline 3000 & 5 & 8000 & 2 \\
8000 & 15 & 10000 & 2 \\
16000 & 15 & 24000 & 2 \\
32000 & 15 & 32000 & 2 \\
40000 & 15 & 40000 & 2 \\
48000 & 15 & 48000 & 3600 \\
\hline
\end{tabular}

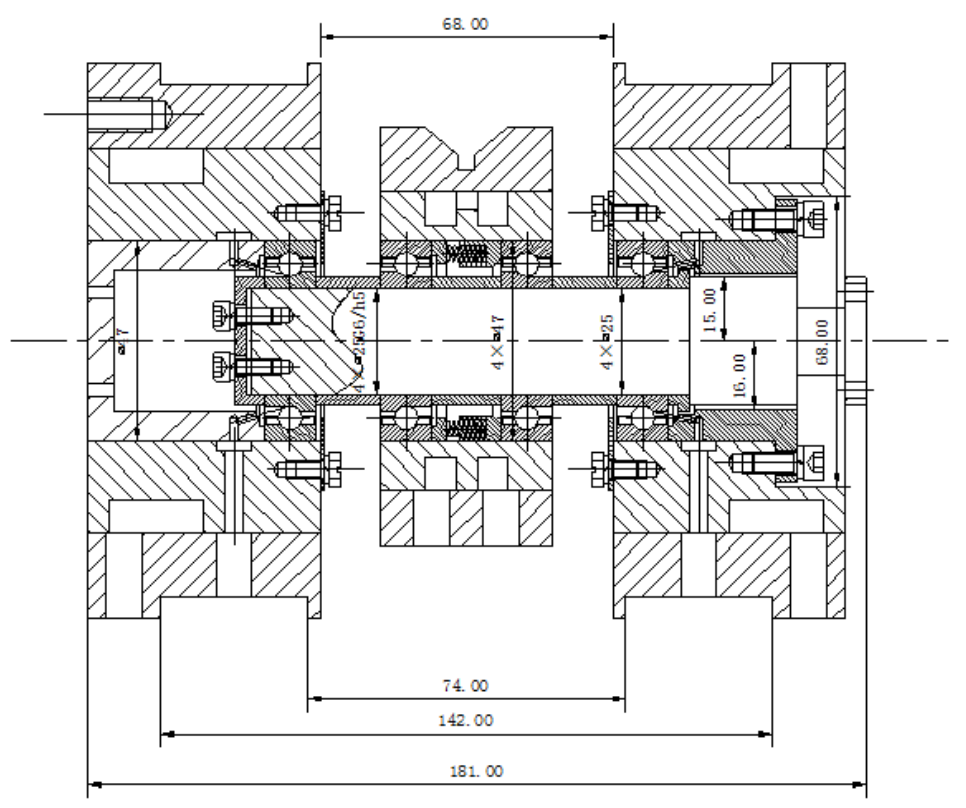

Fig.2. Experimental head structure of the bearing test machine

\section{Analysis of the Experimental Data}

Table 1 show that the removal of visible grease, but a part of the grease still remains on the surface of the rolling element and raceway. This part of the grease probably accounted for the sealing full 
space of 8 to 9 percentages. The above part of space plus the sealing static space that the percentage of occupied was 35.8 percentages which could reach to about 44 percentages. Theoretically, if the amount of grease added did not exceed this value, the grease would not be extruded in the running process of the bearing. It can be seen that 40 percentages filling grease amount does not overflow, while 50 percentages filling grease amount of grease extrude. So the experiments did not need to be done on the bearings where the filling amount of grease was more than $50 \%$.

The experimental data were derived from the computer monitoring program. The data include the prolong time of experiment, the temperature of the bearing outer ring and so on. Data of different grease amount were put into a line chart to be compared(as shown in Fig.3 and fig.4).Time of experiment was carried out as the independent variable, and the temperature of the bearing outer ring was used as the dependent variable.

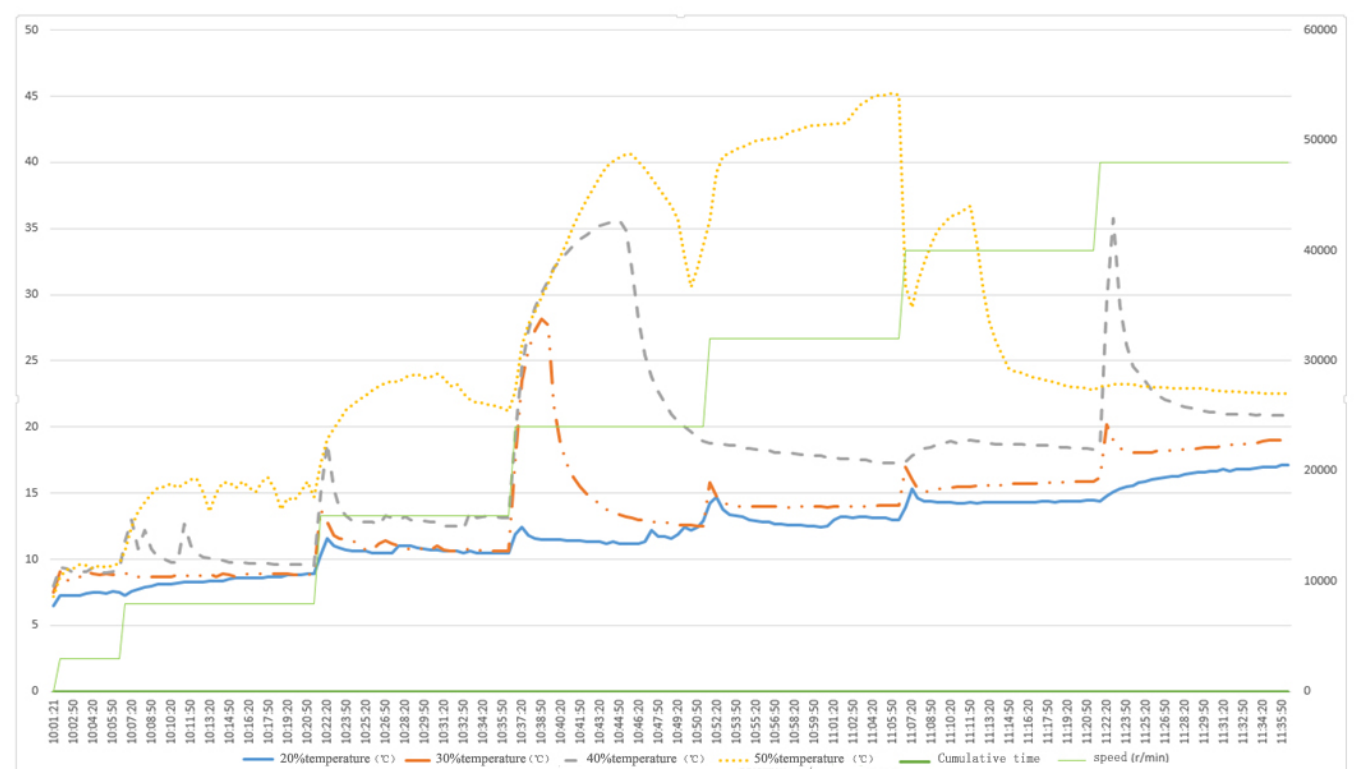

Fig.3. contrast of temperature rising during running-in phase

Figure 3 shows some features of running-in phase. The higher bearing consists of grease, the higher its temperature rising. When the bearing test speed reached the maximum, the bearing temperature tended to be stable. This time, there was only a slight difference in the bearing temperature of different grease adding amounts, which was only $2^{\circ} \mathrm{C}$.In addition, when the bearing was in the running-in phase, the bearing temperature would not exceed $70^{\circ} \mathrm{C}$.

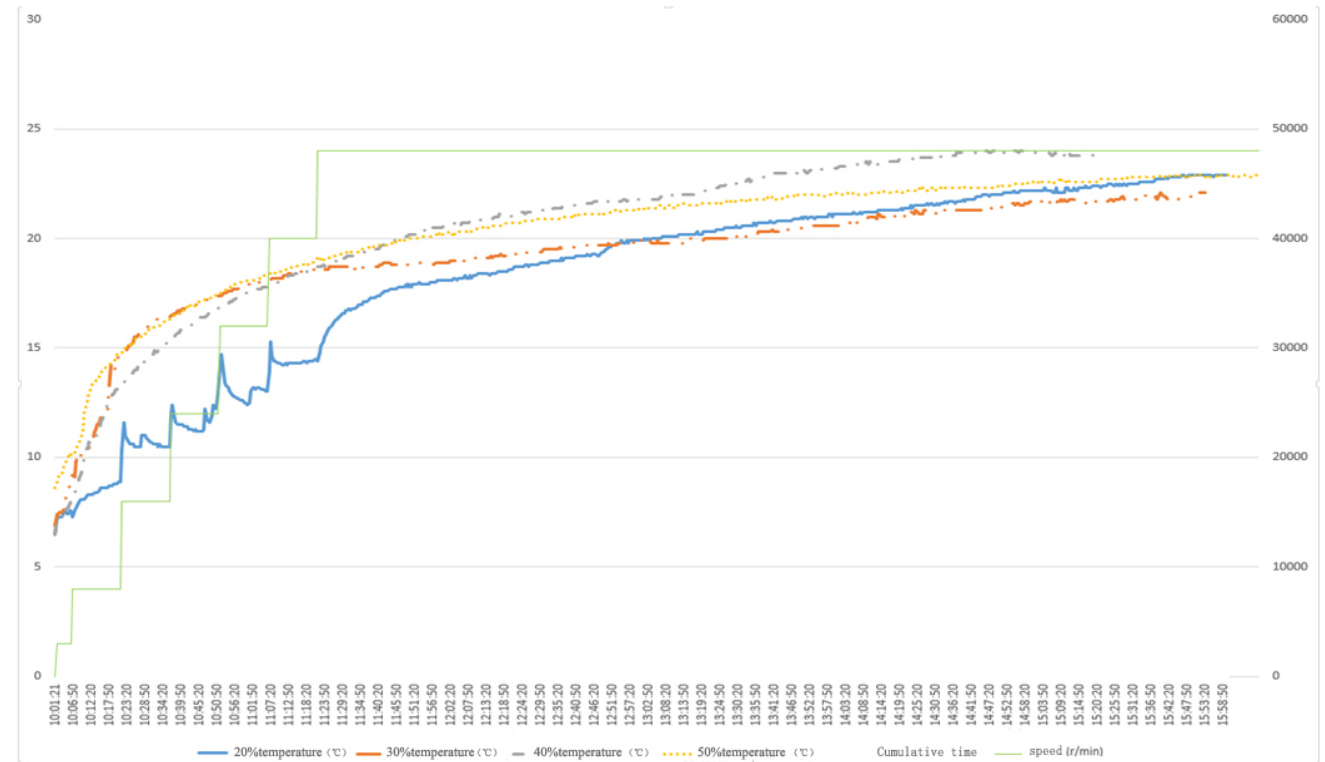

Fig.4. contrast of temperature rising during stationary phase 
The bearing temperature rising curves are shown in fig. 4. It can be seen in fig.4 that the temperature rising curves are basically the same as the different grease adding amount of the bearings. Here, the temperature rising behaves as a logarithmic growth trend. In different temperature rising curves, the same results were eventually obtained, and the value is less than $25^{\circ} \mathrm{C}$.

When the amounts of grease injected into the bearing were between 20 and 50 percentages, and the visible grease on the bearing has been removed, the amount of grease remaining in raceway and rolling element was approximately the same. It could be known from above that the excess of the filling grease amount was stored in the sealing static space on both sides of the seal ring. So when the grease was not squeezed out and the temperature was not too high, the grease should be added as much as possible. This is beneficial to the service life of the bearing, especially for precision bearings because the life of precision bearing depends mainly on lubrication life.

Experimental results show that the bearing temperature rising during running-in phase was increased with the increasing of the filling grease amount, but the maximum increase in temperature would not exceed $70{ }^{\circ} \mathrm{C}$. During stationary phase, the bearing temperature was basically consistent and its value was close to $25{ }^{\circ} \mathrm{C}$. Combined with all the experimental data, the optimum filling grease amount could be got. When the static space ratio was 35.8 percentages, the optimum adding amount of grease could be obtained. The optimum adding amount of grease for the same type of bearings with different sizes can be determined according to the static space ratio. The calculation method of the static space ratio is nearly the same as refer to the above method.

\section{Summary}

A computational method of static space ratio has been proposed in this paper. The bearing performance is tested using the filling grease amount gradient. On the basis of the above, method for the optimum filling grease amount of high-speed sealed angular-contact ball bearings are obtained. Based on experimental model, the effects of the amounts of grease on the bearing can be compared under different working conditions. Optimal bearing application parameters can be found out. This method can provide references to bearing utilizing.

\section{Acknowledgement}

The research was financially supported by the National Natural Science Foundation of China under project No.:U1404517.

\section{References}

[1] LI Dong-ya, YANG Hao-liang and XIAO Ru-feng: Feasibility Analysis of Grease Lubrication Instead of Oil-Mist Lubrication for High-speed Motorized Spindle, Mechanical \& Electrical Engineering Technology Vol. 44 (2015), p. 94-96

[2] LI ZhaoKun, LEI Jianzhong, XU Haifeng, etc: Current Status and Development Trend of Bearing Steel in China and Abroad: submitted to journal of Iron and Steel Research. Forum Vol.83-87(2016), PP: 1-12

[3] H. C. Lu, X. L. Li, Q. C. Wang and M. L. Cao: Experimental Analysis on Lubricating Life for Synthetic Complex Lithium Soap Grease, Bearing No. 4(2015), p. 35-38

[4] X. T. Xia, in: Rolling Bearing Manufacturing Technology, edtied by china machine press, Beijing (2007)

[5] J. X. Xue, B. Zhao, and G. F. Guo: Key Engineering Materials, Vol .455 (2011), p. 686-689 